\title{
MEASURING THE SPATIAL READINESS OF AMBULANCE FACILITIES FOR NATURAL DISASTERS USING GIS NETWORKS ANALYSIS
}

\author{
Anas Awad ${ }^{1}$, Haytham $\mathrm{Ali}^{2}$, Sohaib K. M. Abujayyab ${ }^{3 *}$, Ismail. R. Karas ${ }^{4, a}$, Dyah Respati Suryo Sumunar ${ }^{5}$ \\ ${ }^{1}$ Dept. of Geography Education, Universitas Nigri Yogyakarta, Jl. Colombo Kampus Karangmalang, Gedung Rektorat Lt. 3 , \\ Yogyakarta- Indonesia, anas.m.awd@gmail.com \\ ${ }^{2}$ Dept. of Geography, social Sciences Institute, Istanbul University, Beyazit, 34452, İstanbul Turkey - haytham.ali@ ogr.iu.edu.tr \\ ${ }^{3}$ Dept. of Geography, Karabuk University, Demir Celik Campus, 78050 Karabuk/Turkey - sjayyab@karabuk.edu.tr \\ ${ }^{4}$ Dept. of Computer Engineering, Karabuk University, Demir Celik Campus, 78050 Karabuk/Turkey - ismail.karas@karabuk.edu.tr \\ ${ }^{5}$ Dept. of Geography Education, Universitas Nigri Yogyakarta, Jl. Colombo Kampus Karangmalang, Gedung Rektorat Lt. 3 , \\ Yogyakarta-Indonesia, dyah_respati@uny.ac.id
}

\author{
a Commission IV, WG IV/1
}

KEY WORDS: Disaster Management, ambulance facilities, natural disasters, GIS, networks analysis, volcanic disasters

\begin{abstract}
:
The massive disasters that arise by nature and humanity are significantly leads to several losses in lives and infrastructures. Disasters such as chemical explosions, flash floods and volcanoes. The high level of preparedness from the governments and administration authorities and ambulance services can significantly reduce the losses in lives. The aim of this paper is to measure the spatial readiness of ambulance facilities for natural disasters using GIS networks analysis. The measurement performed based on three standards, the area covered by the ambulance service, speed of service and the proportion to the population. ArcGIS spatial analysis and network analysis tools employed to develop the coverage maps of the three measured standards. According to the analysis, 94.4\% from the study area appeared within the standard distance $(20 \mathrm{~km})$ from the ambulance stations, while $91 \%$ from the study area appeared within the time response standard (15 minutes) from the ambulance stations. The study area has a deficit of 256,714 people and needs 5 additional ambulances to achieve the demographic standard. The main recommendation of this study is to apply this methodology regularly in the study area to avoid any weakness before the disasters and to increase the level of preparedness.
\end{abstract}

\section{INTRODUCTION}

The humanity and planet are continually presented to disasters that might be brought about by natural or human activities. An example of natural disasters is volcanoes, earthquakes, desertification, and floods (Abd El Karim \& Awawdeh, 2020). In addition, an example from the man-made disasters is industrial pollutions, epidemics, pandemics, nuclear bombs and deadly missiles, and explosions from chemical materials. The disasters lead to losses in human lives, losses in material, and infrastructure deterioration (Aitsi-Selmi, Egawa, Sasaki, Wannous, \& Murray, 2015).

At the local and global level, the spatial distribution and spatial coverage of ambulance facilities become an important issue (Murad, 2018). The suitable spatial distribution and spatial coverage of ambulance facilities provide a high preparedness level for the authorities. The high preparedness level help to reduce the released risks and decrease the losses in human lives during and after the disasters. Several countries have formed specialized laboratories to mitigate the disaster results through increasing the preparedness level of ambulance facilities. The continuous evaluation and measuring the preparedness of ambulance facilities is a substantial issue to mitigate the losses. Several countries and institutes formed local and international standards to manage the spatial distribution of the ambulance stations (International Institute for Sustainable Development, 2015).

\footnotetext{
* Corresponding author
}

The aim of this paper is to measure the spatial readiness of ambulance facilities for natural disasters using GIS networks analysis. The measurement performed based on three stan. Lastly the conclusion. The remainder of this paper contains the methodology section. The result section consisting of the analysis using the three standards. Lastly the conclusion.

\section{METHODOLOGY}

The application of GIS networks analysis to measure the preparedness of ambulance facilities applied in Sleman Regency. The area of Sleman Regency is $574.82 \mathrm{~km} 2$, which represents $18 \%$ of the total area of DIY Province. Sleman Regency area is $110^{\circ} 13^{\prime} 00^{\prime \prime}$ - 10 $10^{\circ} 33^{\prime} 00^{\prime \prime}$ East Longitude and 7034'51"- 7047'03" South Latitude (Figure 1).

The Sleman province selected as the study area because it consisting an active volcano called Merapi. The area is exposed to the effect of the volcanic materials and risk at any time. Thus, measuring preparedness is very necessary and have to be performed regularly.

The data of the analysis have been collected from competent authorities in Indonesia (BPBD SLEMAN - BPBD DIYIndonesian Red Cross and Statistics Indonesia BPS- Sleman District Health Office). The obtained data are road network, provinces border, local border, population distribution, ambulance centers and urban area. The locations of the ambulance centers presented in Figure 1. 
ArcGIS 10.5 software with network analysis extension utilized in this study to generate and prepare the spatial and tabular data (Abdelkarim, 2019; Hasnat, Islam, \& Hadiuzzaman, 2018). In addition, several local and international standards collected. At this stage errors in the road networks have been addressed and confirmed with satellite imagery and fieldwork. The correctness of facilities locations verified maps using (GPS, Aerial images, and Google Earth). The in Indonesia are classified by Road Status to (National Road - Provincial road - City Roads - Other roads trails). The roads permitted speed, type and length showed in Table 1.

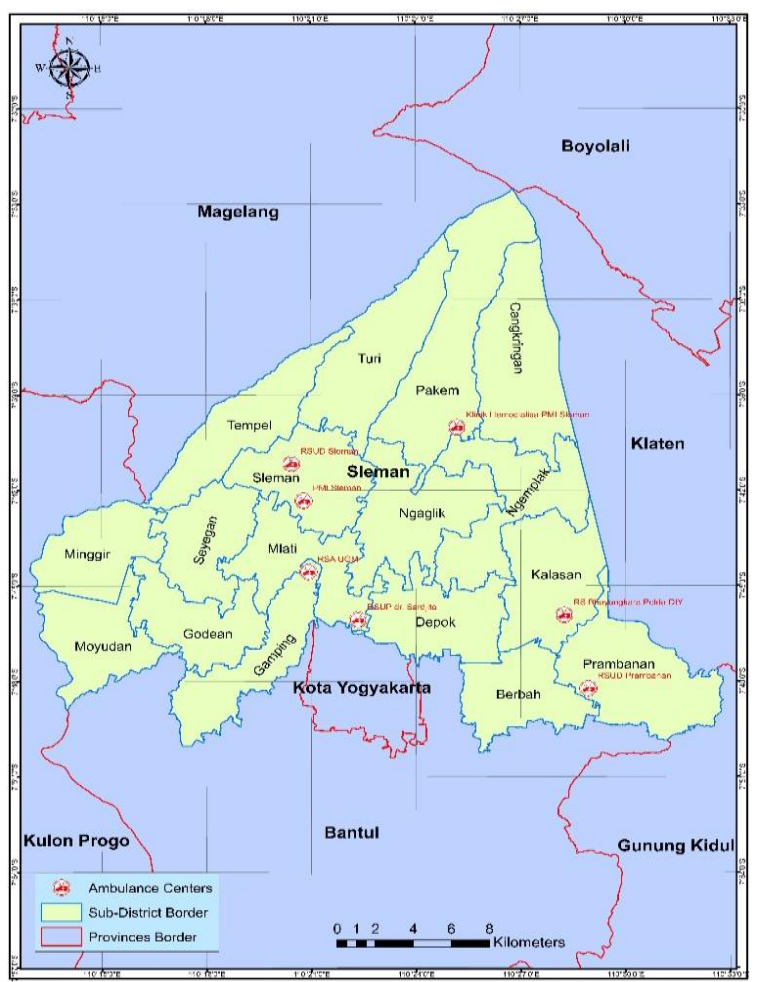

Figure 1 Study area (Sleman Province).

Table 1. Road types - Road speed - Road length.

\begin{tabular}{|c|c|c|}
\hline Road type & Speed $(\mathrm{km} / \mathrm{h})$ & $\begin{array}{c}\text { Road length / } \\
\mathrm{km}\end{array}$ \\
\hline National Road & 100 & 50.11 \\
\hline Provincial road & 80 & 110.77 \\
\hline City Roads & 50 & 626.18 \\
\hline $\begin{array}{c}\text { Other roads } \\
\text { (trails) }\end{array}$ & 30 & 2986.48 \\
\hline
\end{tabular}

By applying three main standards: (1- Standard of Distance 2Standard of Time 3-Demographic Standard), we can know the capabilities of emergency facilities to cover and service the largest area of the study area. In addition, the three standards show the suitability of the population compares with the number of facilities available in the study area.

\section{RESULTS AND DISCUSSION}

This section consisting three subsections: first analysing the service area for each ambulance centres. second, analysing the time response along the area, and lastly, analysing the demographic standard.

\subsection{Distance Standard}

The specified service area for each ambulance center according to the Saudi standard specifies the specific area of each ambulance with a radius $(4-8 \mathrm{~km})$. While the American standards adopted that the service area for ambulance circle diameter $(25 \mathrm{~km})$ (Abd El Karim \& Awawdeh, 2020). The American Standard is adopted by the Palestinian Red Crescent Society, which is responsible for ambulance and emergency services in the Palestinian territories. In Indonesia, the importance of rapid access and providing emergency services to society is less than $20 \mathrm{~km}$.

The result of the distance standard illustrated in Figure 2. according to the distance standard the served area is $20 \mathrm{~km}$ from the ambulance stations in the study area cover an area of 542.32 $\mathrm{km} 2$, which constitutes $94.4 \%$ from the study area. This is a large percentage compared with the area not covered by the service. The area outside the serviced area is 31.9 square kilometers and constitutes 5.5\%. Looking at the results, the ambulance service in the study area according to the distance standard included most of the study area, except some agricultural areas that do not contain population density. Therefore, the target has been achieved, and the standard and number of ambulance stations present are appropriate according to the standards of the Indonesian Ministry of Health.

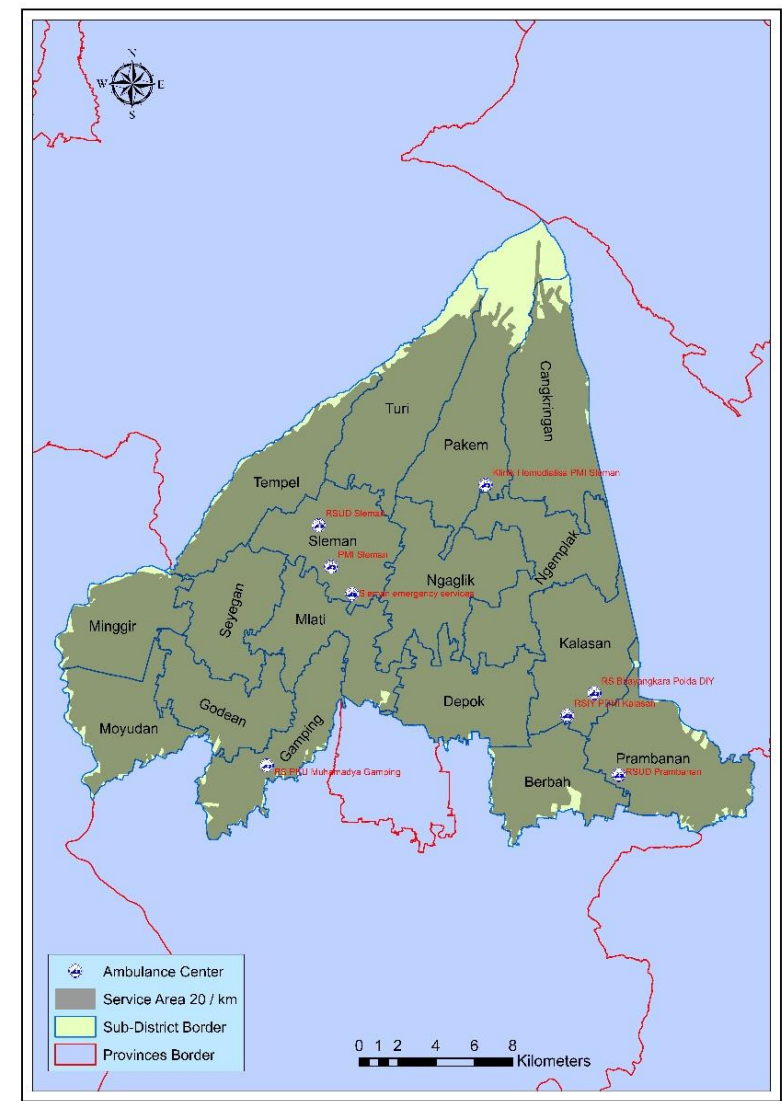

Figure 2. The service area of Ambulance centers in the study area based on the distance standard $(20 \mathrm{~km})$. 


\subsection{Time response standard}

Time response standard means the time allowed from the moment the ambulance is launched to the area of the accident The speed of response and the arrival of ambulances to the site is extremely important, where it works to reduce the risk and keep the patient or injured alive. The response time varies from country to country and from region to region within the country itself. It depends on the nature of the terrain, road quality, permissible speed, and traffic density. In England, for example, the response time for the first category cases is limited to 7 minutes, while the less serious cases limit the response time to a maximum of 18 minutes. In Yogyakarta, the Indonesian Ministry of Health has set the response time to (15 minutes).

There are several factors that control the speed of response time, namely: Speed on the road: Vehicle speed is less than $40 \mathrm{~km}$ on ordinary roads, $80 \mathrm{~km}$ on the highway, road condition, traffic density, and abide by the laws of the road. Note that the speed limit on the road, according to the Indonesian Ministry of Transport is $(100-80-60-30)$. In addition, the lack of visibility caused by volcanic ash, and the slipping road due to mixed rain with ash reduces the speed of vehicles.

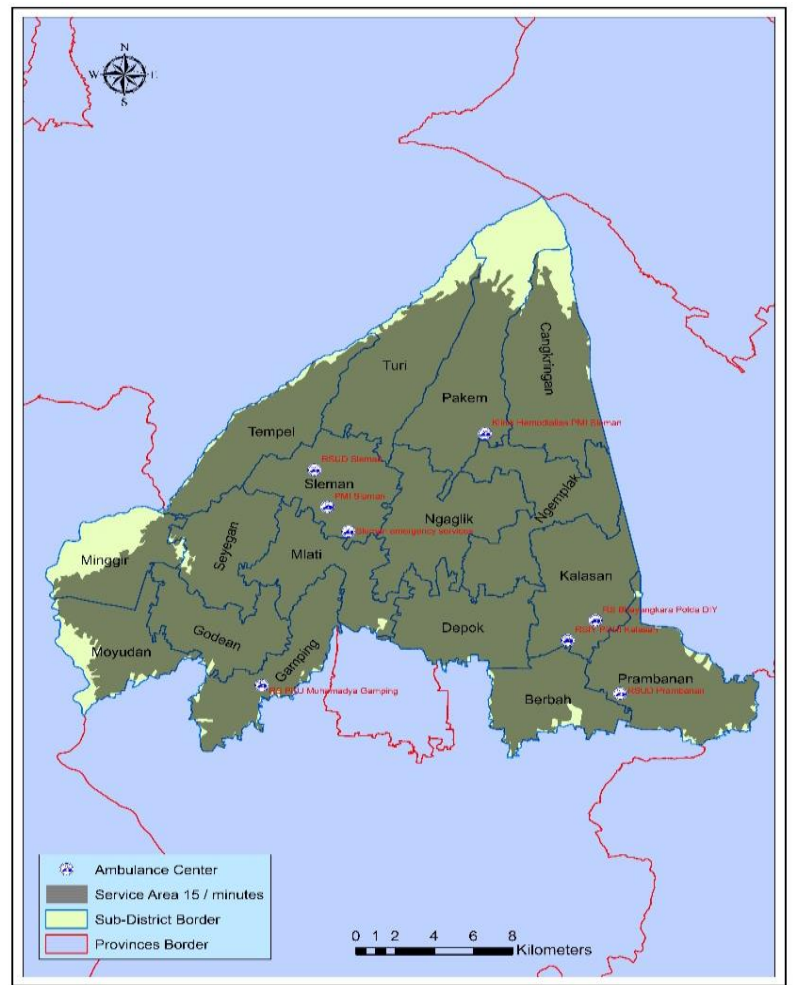

Figure 3. The service area of Ambulance centres in the study area based on the Time Standard (15 minute)

The 8 ambulance centers in the study area cover an area of 523.14 square $\mathrm{km}$ and by $91 \%$. The area outside the ambulance service reached $51.11 \mathrm{~km} 2(8.9 \%)$. These areas are located in separate places. The reason for not covering it is because there are road obstacles or incomplete roads. In addition, the inability of the ambulance to reach that area according to the time standard of 15 minutes. Consequently, there are deficiencies in covering these densely populated places, which necessitates reconsideration either by opening new ambulance centers, especially in the north and west, or working to open new roads that enable ambulances to reach them within the specified time.

\subsection{Demographic Standard}

The World Health Organization (WHO) stipulates that the efficient emergency ambulance delivery to population ratio of every country must be at 1 ambulance to 50,000 persons. This means that for every 50,000 people in a country there should be at least one ambulance ready for their emergence needs. There are 8 centers in the study area to provide an ambulance service presented in Table 2 .

Table 2. The number of Ambulance in Sleman Regency

\begin{tabular}{|l|c|}
\hline $\begin{array}{l}\text { The name of the ambulance } \\
\text { center }\end{array}$ & $\begin{array}{l}\text { Number of } \\
\text { Ambulance }\end{array}$ \\
\hline RSUD Prambanan & 2 \\
\hline RS Bhayangkara Polda DIY & 2 \\
\hline RSUD Sleman & 2 \\
\hline RSIY PDHI Kalasan & 2 \\
\hline RS PKU Muhamadya Gamping & 2 \\
\hline Sleman emergency services (SES) & 2 \\
\hline PMI Sleman & 6 \\
\hline Klinik Hemodialisa PMI Sleman & 1 \\
\hline
\end{tabular}

The number of ambulances in the study area is 19 ambulances. By applying the demographic standard, it found that ambulances serve 950,000 people out of $1,206,714$ people living in the study area. Thus, the study area has a deficit of 256,714 people and needs 5 additional ambulances to achieve the demographic standard. It is necessary to increase the number of available ambulances to be able to serve the largest population.

\section{CONCLUSIONS}

This study reached several conclusions, the most important were: The study area contains a road network at national, provincial, city and local level with a length of $3773.54 \mathrm{~km}$, which provides access to most of the locations. There are 8 ambulance service centers in the study area, 5 of which are located within hospitals, 2 belonging to the Indonesian Red Cross (PMI), and 1 center for Sleman Emergency Service, are managed by Sleman Emergency Service (PSC). The 8 ambulance centers in the study area cover $94.4 \%$ of the area of the study according to the distance standard. In addition, the percentage of served areas according to the standard of arrival time was $91 \%$. When applying the demographical standard, it found that the ambulances serve a population of 950,000 people out of $1,206,714$ people in the study area. Thus, the area has 256,714 people not served by ambulances and need 5 additional ambulances to achieve the demographic standard. The main recommendation of this study is to apply this methodology regularly in the study area to avoid any weakness before the disasters and to increase the level of preparedness.

\section{ACKNOWLEDGEMENTS}

I am very fortunate and grateful to the Ministry of Research, Technology, and Higher Education (RISTEKDIKTI) and Universitas Negeri Yogyakarta for providing me with the (DISS) scholarship.

\section{REFERENCES}

Abd El Karim, A., \& Awawdeh, M. M. (2020). Integrating GIS 
Accessibility and Location-Allocation Models with Multicriteria Decision Analysis for Evaluating Quality of Life in Buraidah City, KSA. Sustainability, 12(4), 1412.

Abdelkarim, A. (2019). Integration of Location-Allocation and Accessibility Models in GIS to Improve Urban Planning for Health Services in Al-Madinah Al-Munawwarah, Saudi Arabia. Journal of Geographic Information System, 11(06), 633.

Aitsi-Selmi, A., Egawa, S., Sasaki, H., Wannous, C., \& Murray, V. (2015). The Sendai framework for disaster risk reduction: Renewing the global commitment to people's resilience, health, and well-being. International Journal of Disaster Risk Science, 6(2), 164-176.

Hasnat, M. M., Islam, M. R., \& Hadiuzzaman, M. (2018). Application of gis for disaster response in dense urban areas: A case study for Dhaka city.

International Institute for Sustainable Development. (2015). A Reporting Service for Environment and Development Negotiations. Earth Negotiations Bulletin, 26(12).

Murad, A. (2018). Using GIS for determining variations in health access in Jeddah city, Saudi Arabia. ISPRS International Journal of Geo-Information, 7(7), 254. 